\title{
Virginia Tech University Chapter Publishes Undergraduate Materials Research in Peer-Reviewed Journal
}

Last fall, members of the Materials Research Society University Chapter at Virginia Polytechnic Institute and State University in Blacksburg unveiled the Alfred Knobler Inaugural Issue of the Journal of Undergraduate Materials Research (JUMR) to the Virginia Tech Materials Science and Engineering Advisory Board. $J U M R$ is a journal created for undergraduate student research in materials science and engineering (MSE).

The creation of this journal realizes Virginia Tech MSE alumnus Alfred Knobler's vision of increasing communication and cooperation between the English and MSE departments as well as among graduate and undergraduate students. This innovative concept provides an opportunity for promoting and publicizing a generally unacknowledged subject, undergraduate research.

Beginning in 2004, the JUMR editorial board took on the responsibility of bringing the idea of a new research journal for undergraduate work, first proposed by Research Faculty and Materials Advantage Chapter advisor Diane Folz and professor and MSE department head David Clark, from concept to reality.

In an interview for The Knobler Review, Ben Poquette, the editor in chief of JUMR and president of the MRS University Chapter said, "There aren't many forums for undergrads to publish their work." He also said, "Graduate students are gaining valuable experience, and the collaboration with the English department should serve to build a strong interdepartmental relationship while improving the quality and professionalism of the journal."

To create this innovative journal, students from the departments of English and MSE formed the student editorial board. The student board members are graduate students Poquette, Davis Eichelberger, Susan Holt, and Navin Manjooran, along

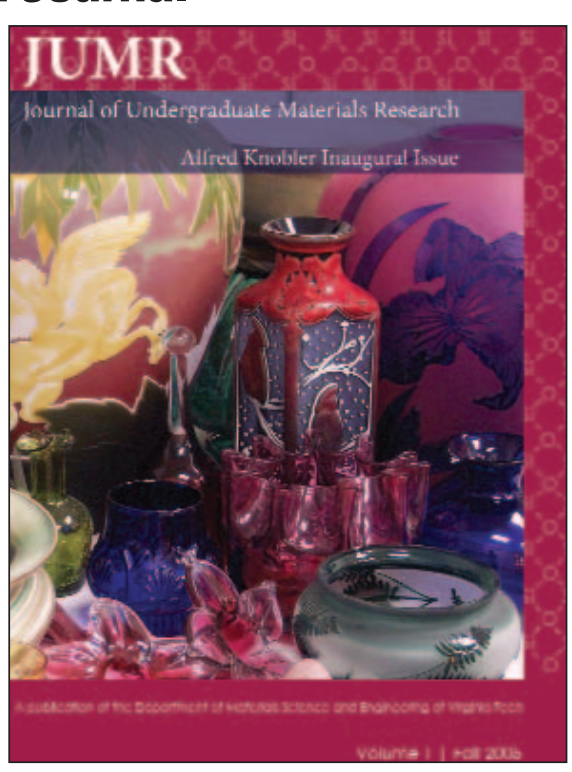
with undergraduate students Steven Kyriakides, Sarah Lewis, and Seth Price.

Six Virginia Tech faculty members-English professor Eva Brumberger and MSE faculty Christine Burgoyne, Diane Folz, Stephen Kampe, Marie Paretti, and Gary Pickrell-form the faculty editorial board, providing review and advice to the student editors. Working together, the two editorial boards shared ideas and expertise to publish the Alfred Knobler Inaugural Issue of $J U M R$. The editorial board also worked with Brumberger's class, Designing Documents for Print, which took on the task of designing the layout for the journal as a service project. Not only does the journal bridge arts and engineering, as Knobler envisioned, but it also brings graduate students, undergraduate students, and faculty together for a common project.

The JUMR student editorial board outlined its primary goals for the journal in the inaugural issue, "We hope that this annual publication will provide a venue for undergraduates to showcase their research, improve their technical writing skills, and be exposed to the rigors of peer-reviewed [graduate student and faculty] publishing... [and] that this periodical will be a strong voice of the research achievements of undergraduates in the field of MSE."

MMR Technologies has developed an

instrument, never before commercially available,

which facilitates convenient and straight-forward

measurement of the Seebeck Effect (thermopower

coefficient) of semiconductors, conductive

ceramics, conductive organics and

polymers, and conventional metals

over a wide temperature range, 80K-730K

$\left(-190^{\circ} \mathrm{C}\right.$ to $\left.+450^{\circ} \mathrm{C}\right)$.

WMR MMR Technologies, Inc.

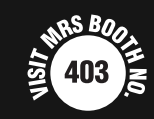

For information call 650 / 962-9620 or visit our website at http://www.mmr.com

For more information, visit-

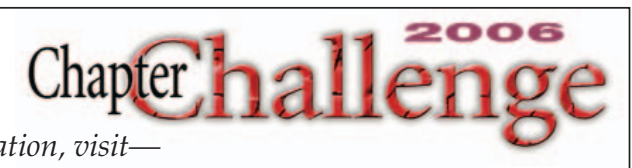

www.mrs.org/university/2006challenge

For more information, see http://www.mrs.org/bulletin_ads 